\title{
Pulses within pulses: Carbon and Nitrogen mobilization patterns across temporal scales, from seasonal snowmelt to rain on snow events in a Rocky Mountain catchment
}

\author{
Robert Hensley ${ }^{1}$, Joel Singley ${ }^{2}$, and Michael Gooseff ${ }^{3}$ \\ ${ }^{1}$ Battelle Memorial Institute \\ ${ }^{2}$ Colorado School of Mines \\ ${ }^{3}$ University of Colorado
}

January 19, 2022

\begin{abstract}
Seasonal snowmelt pulses are the dominant hydrologic feature of most alpine catchments. The majority of annual export of water, carbon and nitrogen occurs within a short window of only a few weeks. This observation has largely been based on relatively infrequent manual sampling, and our understanding of responses to finer-scale variation, "pulses within the pulse", is critically incomplete. Here, we combine high-frequency sensor measurements of dissolved organic carbon (DOC) and nitrate (NO3-N) with historical grab sample data from a high altitude stream in the Rocky Mountains of Colorado. We characterize the linkages between precipitation, snowpack, streamflow, and solute export, over time scales ranging from decades to minutes. At all time scales, discharge (Q) variation was several orders of magnitude larger than concentration $(\mathrm{C})$ variation, making it the dominant control on solute flux rates. Interannual variation in $\mathrm{Q}$, and by extension solute export, appeared correlated to the depth of the winter snowpack, and how late into the spring the snowpack persisted. Seasonally, we observed clockwise C-Q hysteresis, with solute stores becoming depleted as the melt pulse proceeds. Using the sensor data however, we were able to observe individual events. In contrast to the seasonal patterns, these events enriched concentrations, suggesting the persistence of additional DOC and NO3-N stores which can be mobilized within, and even after the main seasonal snowmelt pulse. The historical data suggest that reduced snowpack and earlier snowmelt in the coming decades may result in reduced export of DOC and NO3-N. The sensor data however make this conclusion uncertain, as rain on snow events, which are expected to become more prevalent, appear equally capable of mobilizing solutes.
\end{abstract}

Pulses within pulses: Carbon and Nitrogen mobilization patterns across temporal scales, from seasonal snowmelt to rain on snow events in a Rocky Mountain catchment

Robert Hensley ${ }^{{ }^{*}}$, Joel Singley ${ }^{2}$ and Michael Gooseff ${ }^{3}$

${ }^{1}$ Battelle - National Ecological Observatory Network, Boulder Colorado

${ }^{2}$ Colorado School of Mines, Golden Colorado

${ }^{3}$ Institute of Arctic and Alpine Research, University of Colorado, Boulder Colorado

Corresponding author : hensley@battelleecology.org

\section{Abstract}

Seasonal snowmelt pulses are the dominant hydrologic feature of most alpine catchments. The majority of annual export of water, carbon and nitrogen occurs within a short window of only a few weeks. This observation has largely been based on relatively infrequent manual sampling, and our understanding of 
responses to finer-scale variation, "pulses within the pulse", is critically incomplete. Here, we combine highfrequency sensor measurements of dissolved organic carbon (DOC) and nitrate $\left(\mathrm{NO}_{3}-\mathrm{N}\right)$ with historical grab sample data from a high altitude stream in the Rocky Mountains of Colorado. We characterize the linkages between precipitation, snowpack, streamflow, and solute export, over time scales ranging from decades to minutes. At all time scales, discharge (Q) variation was several orders of magnitude larger than concentration $(\mathrm{C})$ variation, making it the dominant control on solute flux rates. Interannual variation in $\mathrm{Q}$, and by extension solute export, appeared correlated to the depth of the winter snowpack, and how late into the spring the snowpack persisted. Seasonally, we observed clockwise C-Q hysteresis, with solute stores becoming depleted as the melt pulse proceeds. Using the sensor data however, we were able to observe individual events. In contrast to the seasonal patterns, these events enriched concentrations, suggesting the persistence of additional DOC and $\mathrm{NO}_{3}-\mathrm{N}$ stores which can be mobilized within, and even after the main seasonal snowmelt pulse. The historical data suggest that reduced snowpack and earlier snowmelt in the coming decades may result in reduced export of $\mathrm{DOC}$ and $\mathrm{NO}_{3}-\mathrm{N}$. The sensor data however make this conclusion uncertain, as rain on snow events, which are expected to become more prevalent, appear equally capable of mobilizing solutes.

Keywords:snowmelt, carbon, nitrogen, solute flux, in-situ sensors, NEON

\section{INTRODUCTION}

Much of the world's streamflow is derived from mountain snowfall (Viviroli et al., 2007). In the western United States, up to $70 \%$ of streamflow originates from seasonal snowmelt ( $\mathrm{Li}$ et al, 2017). Annual melt pulses provide a critical resource (Sturm et al., 2017), supplying water for drinking, irrigation, and power generation. Understandably, considerable work has gone into characterizing the hydrology of melt pulses, particularly the response to warming temperatures and reduced snowpack (e.g. Bales et al., 2006; Rauscher et al., 2008; Dudley et al., 2017; Marshall et al., 2019). As the principle hydrogeochemical and ecohydrological forcing in most montane environments, equal effort has gone into understanding processes controlling the chemistry of snowmelt (Campbell et al., 1995; Williams et al., 1996a; Brooks et al., 1996;), and the role of melt pulses dynamics in the retention or export of carbon and nitrogen from catchments (Sickman et al., 2001; Meixner et al., 2003; Sickman et al., 2003; Sebestyen et al., 2008).

Stream water chemistry represents the concatenation of all processes occurring in the upstream watershed (Mulholland and Hill, 1997). For snowmelt dominated catchments these processes include atmospheric deposition (Williams et al., 1991a; Sievering et al., 1992), biogeochemical cycling within the winter snowpack and subnivean zone (Brooks et al., 1996; Williams et al., 1996a), and delivery to and export in the stream (Brooks and Williams, 1999; Williams et al., 1991b). Often, concentrations of dissolved carbon and dissolved nitrogen tend to increase rapidly with the onset of the seasonal melt, reaching a maximum several weeks before the peak in discharge (Q) and then decline rapidly (Hornberger et al., 1994; Boyer et al., 1997; Sickman et al., 2001). This "first flush" response has been interpreted as rapid mobilization of limited stores which have built up within the catchment soils during periods of lower flow (Baron et al., 1991; Sickman et al., 2001). Unsurprisingly, inter-annual variability in the depth of snowpack and melt pulse timing can exert considerable influence on carbon and nitrogen processing and transport (Brooks and Williams 1999; Sickman et al., 2003). Understanding these relationships is critical in predicting the response of watersheds to a changing climate.

Notably, most of these studies have relied on grab sampling, with frequencies ranging from daily to weekly. Advancements in field deployable water chemistry sensors have revolutionized the frequency at which measurements can be collected (Rode et al., 2016), allowing us to better characterize processes varying over shorter time scales (Pellerin et al., 2012). Within the melt pulse, rain-on-snow (ROS) events and daily freeze-thaw cycles can generate "pulses within the pulse". Summer rainfall can also generate higher Q events outside the seasonal melt pulse window. This additional Q variation can also profoundly impact dissolved carbon and nitrogen concentrations in snowmelt dominated streams (Casson et al., 2014; Koenig et al., 2017), but is only apparent when high frequency sampling is employed (Pellerin et al., 2012). While of short duration relative to the melt pulse, these events may still constitute an important component of the catch- 
ment flux budget and may provide insight into the potential for mobilization of additional solute pools not depleted by the seasonal pulse. They are also likely to become increasingly common as warmer temperatures result in a greater fraction of annual precipitation falling as rain rather than snow.

Here, we analyze in-situ sensor-based datasets from a snowmelt dominated catchment in the central Rocky Mountains and characterize hydrologically driven variability in stream concentrations (C) of dissolved organic carbon (DOC) and nitrate-nitrogen $\left(\mathrm{NO}_{3}-\mathrm{N}\right)$ across multiple scales. First, we test the hypothesis that a deeper and more persistent winter snowpack will produce a larger and more prolonged spring melt pulse. If $\mathrm{Q}$ is the dominant control on mass flux, this will in turn result in greater export of solutes. Second, we hypothesize that high-frequency measurements will reveal finer-scale, event-driven variation of C-Q relationships. We test whether the C-Q dynamics of these events (e.g. dilution versus enrichment) differ from those observed at seasonal scales. We also test whether inability to account for this high-frequency variation in $\mathrm{C}$ (e.g. relying on grab sampling vs high frequency sensor-based measurements) substantially alters the estimated annual solute flux. Finally, we place the results in the context of climate change projections and what they suggest for export/retention of carbon and nitrogen from alpine catchments in the coming decades.

\section{METHODS}

Como Creek (Figure 1) is located in the Niwot Ridge Long Term Ecological Research (LTER) site in the state of Colorado. Located just east of the North American continental divide, it has an area of approximately $5 \mathrm{~km}^{2}$, with elevations ranging from 3,000-3,600 $\mathrm{m}$ above sea level. This makes it one of the highest instrumented catchments anywhere in the world. It experiences long cold winters, and short cool summers; mean air temperatures for January are $-12^{\circ} \mathrm{C}$, and mean temperatures for July are $12^{\mathrm{O}} \mathrm{C}$. The average annual precipitation is $730 \mathrm{~mm}$, with roughly two thirds as snowfall (snowfall values are reported in snow-water equivalent; SWE). The majority of the watershed is forested, consisting of Engelmann spruce (Picea engelmannii), subalpine fir (Abies lasiocarpa), limber pine (Pinus flexilis), lodgepole pine (Pinus contorta var. latifolia) and quaking aspen (Populus tremuloides). Approximately 10\% of the watershed is above treeline, consisting of alpine tundra and scree slopes.

We obtained four years (Oct 2018 - Sep 2021) of high frequency data from the National Ecological Observatory Network (NEON). NEON (https://neonscience.org) is a National Science Foundation-funded network of monitoring sites throughout the United States providing long-term, open-access ecological data (Goodman et al., 2015). Since 2017, NEON has maintained a monitoring reach along Como Creek, instrumented with a standardized suite of automated sensors. Stream stage is recorded using AquaTroll 600 vented pressure transducers (In-situ; Fort Collins CO). Bi-weekly manual Q measurements are used to develop rating curves and estimate continuous Q. Rating curves are created for each water year (defined as October 1 through September 30). Water quality measurements, including specific conductance (SpC), dissolved oxygen (DO), and fluorescent dissolved organic matter (fDOM) are measured at one minute intervals using an EXO2 multiparameter sonde (YSI; Yellow Springs $\mathrm{OH}$ ). Stream $\mathrm{NO}_{3}-\mathrm{N}$ is measured using a submersible ultraviolet nitrate analyzer (SeaBird Scientific, Bellevue WA) configured to take a 20 measurement burst at 15 minute intervals. The first 10 bursts of each measurement are discarded to allow the SUNA lamp sufficient time to warm up. Concentrations reported in $\mu \mathrm{M}$ were converted to $\mathrm{mg}-\mathrm{N} \mathrm{L}^{-1}$ using the molar mass. The sensors remain installed throughout the winter, measuring concentrations in the liquid water under the ice and snow cover. Both the EXO2 and SUNA were equipped with automated wipers to prevent biofouling. They are also manually cleaned bi-weekly, and calibrated monthly. A time-lapse video of the stream using images from the NEON monitoring location is included as Video 1. Additional images, including real-time, are available from the PhenoCam Network (https://phenocam.sr.unh.edu/webcam/sites/NEON.D13.COMO.DP1.20002/).

NEON also collects bi-weekly grab samples of stream water chemistry. Samples are collected and stored on ice until analysis at the EcoCore laboratory at Colorado State University. In addition to major cations and anions, grab samples are analyzed for DOC, total organic carbon (TOC), $\mathrm{NO}_{2}+\mathrm{NO}_{3}-\mathrm{N}$ (of which $\mathrm{NO}_{3}-\mathrm{N}$ is the overwhelming majority in Como Creek), ammonium $\left(\mathrm{NH}_{4}-\mathrm{N}\right)$, total dissolved nitrogen (TDN), and total nitrogen (TN). Grab samples of these additional species allowed us to contextualize the sensor-based DOC and $\mathrm{NO}_{3}-\mathrm{N}$ measurements in terms of the total $\mathrm{C}$ and $\mathrm{N}$ budgets. 
We used the neonUtilities R package (Lunch et al., 2021), to download the following publicly available NEON datasets: Continuous discharge (NEON 2021a), Water quality (NEON 2021b), Nitrate in surface water (NEON 2021c), Temperature in surface water (NEON 2021d) and Chemical properties of surface water (NEON 2021e). Quality flagged measurements were excluded from our analysis; this constituted a relatively small fraction of the total data $(\sim 5 \%)$ and the majority of these were periods in winter when the stream froze to a depth where the sensors became encapsulated in ice and were no longer measuring concentrations in the liquid water beneath. Because they occured when the stream was not flowing, their omission does not substantially impact annual flux estimates. In a few instances, NEON maintenance and calibration records were used to correct for drift or calibration offsets in the data. Datasets published at higher frequencies (e.g. water quality) were averaged to 15 minute intervals to match nitrate in surface water, which had the lowest temporal resolution. A linear regression between bi-weekly manual DOC measurements and corresponding sensor fDOM measurements was used to estimate continuous DOC from the fDOM timeseries. Multiplying DOC and $\mathrm{NO}_{3}-\mathrm{N}$ concentrations by the corresponding $\mathrm{Q}$ measurement, we calculated a continuous record of DOC and $\mathrm{NO}_{3}-\mathrm{N}$ flux. The na.spline function in the zoo $\mathrm{R}$ package was used to fill short gaps of less than 6 hours. Two larger concentration gaps (fDOM from 24 May to 4 June 2018 and $\mathrm{NO}_{3}-\mathrm{N}$ from 27 June to 1 Aug 2019) were filled using linear interpolation. The effects of uncertainty in this concentration approximation on flux values are expected to be relatively small given that $\mathrm{Q}$ is expected to be the primary driver. All other major gaps were left unfilled because they occurred during periods of little to no flow and were deemed to exert almost no influence on annual flux budgets.

To quantitatively compare interannual variability, we determined the date of the centroid of the annual melt pulse, the annual water yield (WY; cumulative Q divided by watershed area), and the annual export of DOC and $\mathrm{NO}_{3}-\mathrm{N}$. The NEON precipitation gage is located next to the eddy flux tower, high on Niwot ridge, at an elevation much higher than most of the catchment. Instead, we obtained precipitation and snowpack data was from the National Water and Climate Center Snow Telemetry (SNOTEL;https://www.wcc.nrcs.usda.gov/snow/) Niwot station (ID 663), which is located near the center of the Como Creek catchment and likely more representative. It also has a much longer period of record. From these data we calculated the total annual precipitation, maximum depths of annual snowpack, and the date in the spring when the snowpack depth dropped below $10 \mathrm{~cm}$. We then compared these values with the annual melt pulse and solute flux metrics calculated above.

For each solute we determined the coefficients of variation (CV) for discharge and concentration to determine which constituent component of flux exhibited the larger degree of variation, and thus acted as the primary control. We calculated Gini coefficients $(\mathrm{G})$ to quantitatively characterize the temporal inequality in flux (Jawitz and Mitchell et al., 2011). Commonly used to characterize the distribution of wealth, a Gini coefficient of zero represents complete equality (i.e. a constant mass flux rate) while a value of one represents complete inequality (i.e. entire flux in one instant).

For each solute we generated C-Q plots and fit the log-transformed data with a linear regression (i.e. a power function in un-transformed data) to determine whether they exhibited an enrichment, dilution, or chemostatic response (Godsey et al., 2009). A positive slope indicates enrichment, a near-zero slope indicating relative chemostasis, and a negative slope indicates dilution; a slope of exactly -1 is a special case indicating perfect dilution of a constant flux of solute. We carefully examined the C-Q relationships for any signs of hysteretic behavior at both annual and event time scales, noting the directionality. Clockwise hysteresis indicates relative enrichment of earlier arriving water, while counter-clockwise hysteresis indicates relative enrichment of later arriving water (Evans and Davies, 1998).

The NEON sensor array has only been deployed since fall 2017, providing four years of data at the time of this analysis. To better characterize drivers of inter-annual variability, and better contextualize the results in the context of long term trends, we supplemented this data with historical LTER records of daily average Q (Williams et al., 2021) and weekly grab samples from 2004 through 2014 (Williams 2021). This data was publicly available from the Environmental Data Initiative (EDI) data portal (https://portal.edirepository.org/). To understand the potential for the different sampling frequencies of the historic data to influence estimates 
of annual flux, we downsampled our sensor-based solute measurements to match the intervals used in the historic sampling (daily average Q and concentration measurements from every Monday at 12:00). Using these values, we re-calculated the estimated annual fluxes of $\mathrm{DOC}$ and $\mathrm{NO}_{3}-\mathrm{N}$ and compared with the estimates made using the 15 minute data.

\section{RESULTS}

The annual snowmelt pulse typically began in early May, peaked in early June, and had subsided by early July (Figure 2). Seasonal increases in concentrations of DOC and $\mathrm{NO}_{3}-\mathrm{N}$ appeared to precede the melt pulse by several weeks, typically peaking in April to May and then, especially in the case of $\mathrm{NO}_{3}$-N, already declining well before Q peaked in June. Similar temporal patterns were observed in the historic data collected by the LTER (Supporting Figure 1).

There was considerable interannual variation in the timing and magnitude of the snowmelt pulse among the four study years (Table 1). For example, the centroid of the pulse in 2019 was over 3 weeks later than in 2018, and the water yield for 2019 was over $50 \%$ higher than 2018. The historical LTER records showed similar interannual variation (Supporting Table 1).

The annual flux estimates from downsampled sensor data were not substantially different from those made using the whole dataset (Table 2), never off by more than $\pm 3 \%$ in any year. This indicates that weekly concentration sampling is likely sufficient for estimating annual fluxes, and that values calculated using the 2018-2021 NEON sensor data can be accurately compared with historical LTER values. We noted that this was not the case if $\mathrm{Q}$ was downsampled to a discrete dailymeasurement rather than a daily average . Because of large diel variation in $\mathrm{Q}$, the time of day chosen for the $\mathrm{Q}$ measurement has the potential to substantially impact annual flux estimates (by up to $\pm 30 \%$ or more!). Because it exerts such a strong influence, high-frequency $\mathrm{Q}$ measurements appear essential for accurately estimating fluxes.

Despite concentrations which were already declining, maximum export of DOC and $\mathrm{NO}_{3}-\mathrm{N}$ (mass flux shown as gray lines in Figure 2) occurred concurrent with the peak of the melt pulse. Over the 4 years of NEON sensor data, the $\mathrm{CV}_{\mathrm{Q}}$ was 2.47 while $\mathrm{CV}_{\mathrm{DOC}}$ was 0.47 and $\mathrm{CV}_{\mathrm{NO}-\mathrm{N}}$ was 0.61 . This made $\mathrm{Q}$ variation the dominant control on flux. Flux was highly unequal in time, with a $\mathrm{G}_{\mathrm{DOC}}$ of 0.87 and $\mathrm{G}_{\mathrm{NO} \text {-N }}$ of 0.82 . Seventy nine percent of the DOC export and $71 \%$ of the $\mathrm{NO}_{3}-\mathrm{N}$ export occurred within just $10 \%$ of the time; the peak weeks of snowmelt.

Globally, fitted C-Q relationships suggest DOC was slightly enriched (Log-Log slope $=0.14$ ), though still in the range (slope $< \pm 0.2$; Godsey et al., 2009) which would be considered relatively chemostatic. $\mathrm{NO}_{3}$ - $\mathrm{N}$ was almost perfectly chemostatic $(\log -\log$ slope $=0.01)$. In contrast, $\mathrm{C}-\mathrm{Q}$ relationships for major conservative solutes (Supporting Figure 2) exhibited moderate dilution responses, though with slopes still far from a value of -1 which would signify a perfect dilution response of a fixed mass flux of solute. Coefficients of variation for conservative solutes (e.g. $\mathrm{CV}_{\mathrm{Na}}=0.64, \mathrm{CV}_{\mathrm{Ca}}=0.46$ ) were also much less than $\mathrm{CV}_{\mathrm{Q}}$, and using $\mathrm{SpC}$ as a surrogate for a continuous conservative ion concentration produces a $\mathrm{G}_{\mathrm{SpC}}$ of 0.75 . Thus, despite the weak dilution response, the majority of conservative ion export also occurs during the melt pulse.

The seasonal increase in DOC and $\mathrm{NO}_{3}-\mathrm{N}$ concentrations which preceded the melt pulse resulted in noticeable clockwise C-Q hysteresis for both solutes over annual time scales (dashed lines in Figure 3a\&b). Within these larger annual hysteresis loops are smaller loops generated by individual precipitation events. These include spring ROS, summer rainfall when no snow is present, and autumn/early-winter snow that quickly melts without becoming snowpack. These events produce consistent enrichment of DOC and $\mathrm{NO}_{3}-\mathrm{N}$, with fitted LogC-LogQ slopes ranging from 0.15 to 0.35 across individual events. These slopes for individual events are distinctly steeper than those observed at seasonal time scales. Concentration variations typically lag Q during such events (Figure 3c-f), producing counterclockwise C-Q hysteresis loops within the larger clockwise seasonal loop (solid line in Figure 3a\&b).

Discharge exhibited significant diel variation during the melt pulse, with peak daily values often $50 \%$ higher than the minima for the same day (Figure 4a). These daily pulses, presumably driven by greater daytime 
melting, typically peak in the late afternoon. $\mathrm{DOC}$ and $\mathrm{NO}_{3}-\mathrm{N}$, as well as $\mathrm{SpC}, \mathrm{DO}$ and Temperature also exhibited varying degrees of diurnal variation (Figures $4 \& 5$ ). SpC was especially interesting in that during the peak of the melt pulse it showed extremely modest diel variation $\left(<0.2 \mu \mathrm{S} \mathrm{cm} \mathrm{cm}^{-1}\right)$ despite large diel variation in $\mathrm{Q}\left(>100 \mathrm{~L} \mathrm{~s}^{-1}\right)$. During base flow however, when diel Q variation was orders of magnitude less, diel Spc variation was considerably greater $\left(1-2 \mu \mathrm{S} \mathrm{cm}^{-1}\right)$.

\section{DISCUSSION}

\subsection{Drivers of inter-annual variability}

Inter-annual variability in the timing and magnitude of the melt pulse appears somewhat, though imperfectly correlated with metrics of precipitation and snowpack. This is likely due to the complex nature of how precipitation translates to runoff in this catchment, and the difficulty in characterizing something as nuanced as snowpack and a melt pulse with singular metrics. Annual WY was only weakly correlated with annual precipitation (Figure 6a), and constituted only around 30-40\% of the latter. This difference is the result of sublimation and evapotranspiration (ET), and is consistent with findings in adjacent catchments (Sueker et al., 2001). Maximum snowpack depth was not correlated with annual precipitation (not shown, $\mathrm{p}=0.71$ ). This can partially be explained by remembering that around a third of the annual precipitation falls as rain, and does not contribute to the snowpack (and may even accelerate melting of the snowpack). This fraction also changes from year to year. For example, 2020 experienced relatively heavy snowfall followed by a relatively dry summer, with $76 \%$ of the annual precipitation falling as snow. In contrast, the reverse was true in 2021 and this fraction was only 58\%. Even then, the maximum snowpack is not a perfect reflection of cumulative snowfall; the region is famous for its Chinook Winds, and some fraction of the snowpack may sublimate.

Timing also appears critically important. For example, 2020 saw rapid early snowpack accumulation, and late season storms pushed the maximum depth to near-record levels in late April (Figure 7b). However, it began to rapidly melt and was gone by mid-May. In contrast, 2021 saw near record low snowpack early in the season and a lower maximum depth, but it ultimately persisted into June. Persistence of the snowpack later into the spring appears to be an important factor in generating a larger melt pulse and a higher annual water yield (Figure 7c). Thus, while annual WY shows some correlation with maximum snowpack depth (Figure $6 \mathrm{~b}$ ), the correlation with the date the snowpack remains above $10 \mathrm{~cm}$ is stronger (Figure 6c). Persistence of the snowpack later into the spring appears a critical factor in generating larger melt pulses. This may be because a greater volume is melting and becoming runoff, versus losses earlier in the season which are more to sublimation.

These larger melt pulses in turn seem to transport a larger mass of DOC (Figure 6e,f). This correlation was less apparent for $\mathrm{NO}_{3}-\mathrm{N}$ mass flux in the years with high frequency data. This potentially has to do with differences in the seasonality of $\mathrm{NO}_{3}-\mathrm{N}$ vs DOC concentrations, with the latter peaking several weeks earlier than the former, and thus less temporally aligned with the $\mathrm{Q}$ peak. It is also worth noting that $\mathrm{NO}_{3}-\mathrm{N}$ is only one component of dissolved nitrogen. Grab samples revealed concentrations of $\mathrm{NH}_{4}-\mathrm{N}$ often comparable to $\mathrm{NO}_{3}-\mathrm{N}$, and by difference suggest the largest component of TDN may be dissolved organic nitrogen (DON). TOC and TN values were almost identical to DOC and TDN, suggesting minimal particulates. Interestingly, TDN concentrations appeared to peak later in the spring than $\mathrm{NO}_{3}-\mathrm{N}$, closer to the annual peak Q. The NEON grab sample dataset is admittedly short (and COVID-19 mitigation protocols further limited grab sampling in much of 2020), but historic samples collected by the LTER seem to confirm this (Supplemental Figure 1c). Flux of TDN is likely to show greater alignment with Q, and respond more strongly to inter-annual variability in the melt pulse (Figure 6f).

Looking at extremes from the historical record (Supplemental Table 1), 2011 had the highest annual precipitation, the deepest maximum snowpack, the latest centroid of the melt pulse, and nearly the highest annual water yield. Unsurprisingly, this resulted in the greatest annual export of DOC and TDN. Conversely, 2012 had the lowest annual precipitation, the shallowest maximum snowpack, the earliest centroid of the melt pulse, and the lowest annual water yield. Again unsurprisingly, this resulted in the lowest annual export of 
DOC, and nearly the lowest of TDN. Similar to what we observed in the high frequency data, years with below average maximum snowpack (e.g., 2010) can still produce above average annual water yield and in turn above average solute fluxes, but only when the snowpack persists later into the spring.

\subsection{Inferences from finer-scale variation}

Using sensors, we were able to observe finer-scale temporal variation in DOC and $\mathrm{NO}_{3}-\mathrm{N}$ C-Q dynamics than are apparent from grab samples. Of particular note, higher Q generated by ROS or other precipitation events resulted in marked enrichment of DOC and $\mathrm{NO}_{3}-\mathrm{N}$ (Figure 3c-h). Notably, this enrichment response required rainfall (or rapidly melting snowfall). Diel variation in Q during melting of the snowpack, though of similar or often even greater magnitude, does not generate the same concentration response as even a small increase in Q due to new precipitation. Furthermore, it occurs during periods when DOC and $\mathrm{NO}_{3}-\mathrm{N}$ concentrations have otherwise shown signs of being depleted. This suggests that recent precipitation-derived increases in Q, as opposed to snowpack derived, are somehow able to mobilize additional solute sources, or short circuit retention along regular transport pathways. The temporal lag between $\mathrm{Q}$ and concentration, and the counter-clockwise hysteresis it produces (Figure 3a,b), suggests it is the later arriving water that is more enriched (Evans and Davies 1998). One potential explanation is that stores of carbon and nitrogen in more distal regions of the catchment, being further from the "drain", are less depleted (e.g., Hood et al., 2006). Rainfall events are able to temporarily establish great connectivity with these regions, and their distance is responsible for the temporal lag. The temporal alignment of high Q and high concentrations makes ROS and other precipitation-driven events "hot moments" for solute transport, generating some of the highest instantaneous flux values observed in the record. However, their relatively infrequent occurrence and short duration mean they are still a much smaller contributor to annual flux budgets than the seasonal melt pulse.

High-frequency measurements also enabled us to observe diel variation. During the melt pulse (Figure 4a), diel Q variation was consistent with greater afternoon melting (Caine, 1992; Lundquist and Cayan, 2002; Kirchner et al., 2020). Following the melt pulse, the timing of peak daily Q shifted to earlier in the day, consistent with effects of riparian ET (Gribovszki et al., 2010; Kirchner et al., 2020). We also observed small, but noticeable diel variation in $\mathrm{DOC}$ and $\mathrm{NO}_{3}-\mathrm{N}$ concentrations. Signal timing was often consistent with daytime production of DOC through gross primary production (GPP), and the coupled assimilatory uptake of $\mathrm{NO}_{3}-\mathrm{N}$ (Heffernan and Cohen 2010). However, we were confounded in our attempt to estimate rates of GPP using the streamMetabolizer R model (Appling et al., 2018), because the diel DO signal exhibited daytime minima instead of expected maxima (Figure 4c \& 5c). To some extent this was the result of effects of diurnal temperature variation on solubility. However, even after accounting for this, the percent saturation still exhibited consistent daytime minima (not shown). One possible explanation is that ecosystem respiration (ER) is stimulated by temperature, and daytime rates of stream ER have been found to be considerably higher than nighttime rates (Tobias et al., 2007; Hotchkiss and Hall 2014). In a narrow, forested stream such as Como Creek, light inhibition by the canopy may limit GPP to a level where daytime enhancement of ER by warmer daytime water temperatures, and the resulting consumption of DO, may become the dominant process. Rates of denitrification are also sensitive to temperature (Rusjan and Mikos, 2010), and this could also potentially explain the diel $\mathrm{NO}_{3}-\mathrm{N}$ signal absent assimilatory uptake. It is quite interesting to note however, that some of the largest diel variation in $\mathrm{NO}_{3}-\mathrm{N}$ (Figure $4 \mathrm{~b}$ ) occurred prior to the melt pulse when the stream was still mostly snow covered, there was almost no diel variation in DO, and temperatures were very near freezing. An alternative explanation is that diel solute variation (including DO) is not primarily biological, but potentially an expression of diel Q variation (Nimick et al., 2011; Hensley et al., 2017). This conclusion is supported by the large diel variation in conservative SpC during much of the year. Unfortunately, parameters which could be used to more definitively constrain biologic versus hydrologic influence (e.x. C and $\mathrm{N}$ isotopes, concentrations of other dissolved gases), are not collected at the sub-daily resolution required.

\subsection{Projections in a changing climate}

Over the past decades, the western United States has experienced declining snowfall (Kunkel et al., 2009; 
Harpold et al., 2012) and earlier melt pulses (Clow, 2010), a trend that is projected to continue (e.g., SiirilaWoodburn et al., 2021). Based on observations that solute fluxes are strongly tied to the magnitude and timing of the melt pulse, this will potentially result in decreased carbon and nitrogen export and greater retention within the catchment. While regionally, the western United States is expected to become dryer, some areas may actually see increased precipitation as a result of local conditions. The leeward side of the central Rocky Mountains appears to potentially be one such case (Kunkel et al., 2009). Indeed, from 1951 to 1994, Niwot Ridge LTER experienced a statistically significant $(\mathrm{p}<0.01)$ increase in annual precipitation of $7.5 \mathrm{~mm} \mathrm{yr}^{-1}$ (Williams et al., 1996b). However, this trend appears to have reversed, or at the very least stalled in the more recent SNOTEL data from 1995 to 2021 (slope $=-3.9 \mathrm{~mm} \mathrm{yr}^{-1} ; \mathrm{p}=0.19$ ).

In addition to the overall volume, the form of precipitation (i.e. snow versus rain) may also change. With warmer temperatures, a greater fraction of precipitation would be expected to fall as rain rather than snow. As illustrated by the sensor data, rainfall events are clearly capable of rapidly mobilizing and transporting solutes, perhaps even more effectively than snowmelt. This suggests that a shift from snow to rain may not result in as large a decline in solute export as otherwise expected. Warmer temperature could also result in more frequent "mini-melt" periods. Modeling studies (Jennings and Molotch, 2020) suggest only a $3^{\circ}$ $\mathrm{C}$ increase is required for much of Como Creek watershed to experience significant melting throughout the winter. More precipitation falling as rain rather than snow, combined with more frequent periods of winter melt would alter the timing of export such that it is more evenly distributed and less condensed into a singular seasonal pulse

Several additional sources of very large uncertainty also remain. In addition to changing precipitation, changing catchment characteristics may also influence stream hydrology. Warmer temperatures will likely result in a general upward migration of the tree line, though temperature is far from the only controlling factor (Bueno de Mesquita et al., 2018). The fraction which is forested has been demonstrated to exert substantial control on rates of evapotranspiration and water yield in nearby catchments (Sueker et al., 2001). It is possible that a shift to an earlier melt pulse, when rates of evapotranspiration are lower, could at least partially offset these losses (Barnhardt et al., 2020). Recent modeling work in Como Creek (Barnhart et al., 2021) has also suggested that expansion of forested area in response to warming temperatures may actually increase streamflow by decreasing snow wind-scour. In short, there is large uncertainty in how temperature driven changes to catchment vegetation will interact to affect catchment hydrology, including runoff.

Another large unknown is how biogeochemical processing of carbon and nitrogen within the catchment will respond to changing temperatures and snow cover. Biogeochemical cycles consist of multiple interconnected and sometimes reciprocal pathways. With the $\mathrm{N}$ cycle for example, atmospheric fixation, mineralization of organic nitrogen, nitrification and denitrification are all sensitive to temperature and soil moisture (e.g., Fisk and Schmidt, 1995; Osborne et al., 2016; Chen et al., 2020; Maslov and Maslova, 2021). Somewhat counterintuitively, reduction in the depth and duration of the insulating snowpack may actually result in colder subnivean temperatures and reduced biological activity (Williams et al., 1998). Snow cover has been identified as a critical control on subnivean microbial processing (Brooks et al., 1996), and by extension, soil water chemistry (Lewis and Grant, 1980). Williams (et al., 1998) projects that increased snow cover will enhance net soil nitrification and result in greater $\mathrm{NO}_{3}-\mathrm{N}$ availability, while a reduction in snowfall will have the opposite effect and result in greater retention. This is strongly supported by the observation that solute flux appears most closely associated with persistence of the snowpack later into the spring (which results in higher discharge but also higher concentrations). While the total snowfall, maximum snowpack depth, and its duration are certainly linked, they are not perfectly correlated. An unseasonably warm spring can quickly melt a deeper than average snowpack, as we observed in 2020. This provides a third example of how changing temperatures over the coming decades can alter the solute export, even if total annual precipitation remains unchanged.

\section{CONCLUSIONS}

Because of their remoteness and inhospitality, high-altitude (as well as high-latitude) snow-melt dominated catchments remain understudied. These catchments contribute a significant fraction of global streamflow 
(Viviroli et al., 2007) and are also among the most susceptible to the effects of changing climate (Adam et al., 2009). Mobilization and downstream transport by river networks are critical processes in carbon and nitrogen cycles. This makes developing a generalized understanding of the solute dynamics of snowmelt dominated catchments, and in particular the response to hydroclimatic perturbation, of global importance. Como Creek represents one of the highest elevation locations we yet have data for.

Using big, open-data is the new frontier in hydrological and ecological sciences (Hampton et al., 2013), and this study relied entirely on publicly available data. We took a network-of-networks approach to combine historical and high-frequency precipitation, snowpack, discharge, and solute data to assess drivers of carbon and nitrogen export from a high altitude stream in the Rocky Mountains. We found that DOC and $\mathrm{NO}_{3}-\mathrm{N}$ fluxes were strongly controlled with discharge, over time scales ranging from minutes to decades. Seasonal snowmelt pulses are the dominant driver of annual solute export. Interannually, the magnitude and timing of the snowmelt pulse, and by extension solute export, was strongly correlated with both the depth and persistence of the snowpack. As in prior studies, we found that clockwise C-Q hysteresis over the snowmelt pulse was suggestive of seasonal depletion of solute pools. Yet, the high-frequency data revealed pulses within pulses from individual events wherein concentrations where enriched and C-Q hysteresis was counter-clockwise indicating that additional DOC and $\mathrm{NO}_{3}-\mathrm{N}$ pools persist and can be readily mobilized, particularly through rain on snow events. While the historical low-frequency grab sample data suggest that reduced snowpack and earlier snowmelt may result in reduced export of $\mathrm{DOC}$ and $\mathrm{NO}_{3}-\mathrm{N}$, the sensor data make this conclusion uncertain, as increasingly prevalent rain on snow events appear equally capable of mobilizing solutes.

\section{ACKNOWLEDGEMENTS}

NEON is a National Science Foundation funded project operated by Battelle Memorial Institute (Award 1724433). We thank H. Schartel, Z. Lafaver, R. Lehrter and the field staff of NEON Domain 10/13 for data collection and sensor maintenance. We thank M. Williams for making historic Niwot LTER data publicly available through EDI.

\section{DATA AVAILABILITY}

All data used in this manuscript is publicly available and can be accessed from the links provided in the References.

\section{FIGURE LEGENDS}

Figure 1. Como Creek, Colorado. The star indicates the sampling location (40.0350 N, -105.5444 W), dashed line is the approximate watershed boundary and green shows the approximate tree line.

Figure 2. Time-series of $\mathrm{Q}(\mathrm{a}), \mathrm{DOC}(\mathrm{b})$ and $\mathrm{NO}_{3}-\mathrm{N}$ (c) from Como Creek. Colored lines are concentration, gray lines are mass flux (concentration $\mathrm{x}$ discharge).

Figure 3. C-Q plots of DOC (a) and $\mathrm{NO}_{3}-\mathrm{N}$ (b) exhibited clockwise hysteresis (dashed lines) over seasonal time scales. At the scale of events, enrichment of DOC $(c, e, g)$ and $\mathrm{NO}_{3}-\mathrm{N}(\mathrm{d}, \mathrm{f}, \mathrm{h})$ typically lagged $\mathrm{Q}$, producing counterclockwise hysteresis (shown as solid lines in a,b).

Figure 4. Onset and peak of 2020 melt pulse. A ROS event occurred on 30 May. While the volume of rainfall was relatively modest $(12 \mathrm{~mm})$, it produced a large increase in discharge (a). This resulted in enrichment of DOC and $\mathrm{NO}_{3}-\mathrm{N}$ concentrations (b).

Figure 5. Late baseflow 2020 showing diel variation in all stream parameters. On 8 Sep, early season snowfall occurred (17 mm SWE), which melted as air temperatures warmed on 10 Sep (a). The relatively small increase in $\mathrm{Q}$ produced a large, and prolonged enrichment of $\mathrm{DOC}$ and $\mathrm{NO}_{3}-\mathrm{N}$ concentrations (b). Axes scales are the same as for Figure 5, with the exception of Q, which is 250x larger.

Figure 6. Annual WY exhibited varying degrees of correlation with various metrics of precipitation and snowpack (a-d). Solute fluxes were in turn strongly correlated with WY (e,f). Colored points correspond to years with NEON sensor measurements, gray are historic LTER data. 
Figure 7. Cumulative precipitation (a), snowpack depth (b), water yield (c) and DOC export (d).

\section{TABLES}

Table 1. Summary of annual snowpack, melt pulse and flux statistics for the 4 years of high-frequency data. +estimates requiring some gap filling.

\begin{tabular}{lllll}
\hline & 2018 & 2019 & 2020 & 2021 \\
Annual precip (SWE mm) & 635 & 706 & 654 & 745 \\
Max snowpack (SWE mm) & 307 & 340 & 480 & 381 \\
Date snowpack $<10 \mathrm{~cm}$ & 16 May & 4 June & 21 May & 4 June \\
Date melt pulse centroid & 29 May & 22 June & 3 June & 11 June \\
Annual water yield (mm) & 150 & 244 & 181 & 218 \\
Annual DOC flux (kg) & $4175+$ & 7798 & 4655 & 6067 \\
Annual $\mathrm{NO}_{3}$-N flux (kg) & 69.1 & $40.4+$ & 58.7 & 70.5 \\
\hline
\end{tabular}

Table 2. Effect on annual flux estimates of down-sampling high frequency data to simulate weekly grab sampling. Down-sampled values can be compared with actual values shown in Table 1 to calculate the percent difference.

\begin{tabular}{lllll}
\hline & Flux (kg) & Flux (kg) & Difference (\%) & Difference (\%) \\
Year & DOC & $\mathrm{NO}_{3}-\mathrm{N}$ & $\mathrm{DOC}$ & $\mathrm{NO}_{3}-\mathrm{N}$ \\
2018 & 4225 & 71.4 & $+1.2 \%$ & $+3.3 \%$ \\
2019 & 7628 & 40.4 & $-2.2 \%$ & $-0.1 \%$ \\
2020 & 4616 & 57.5 & $-0.8 \%$ & $-2.0 \%$ \\
2021 & 6120 & 72.8 & $+0.9 \%$ & $+3.3 \%$ \\
\hline
\end{tabular}

\section{REFERENCES}

Adam, J.C., Hamlet, A.F. and Lettenmaier, D.P., 2009. Implications of global climate change for snowmelt hydrology in the twenty-first century. Hydrological Processes: An International Journal, 23(7), pp.962972.doi:10.1002/hyp.7201

Appling, A.P., Hall Jr, R.O., Yackulic, C.B. and Arroita, M., 2018. Overcoming equifinality: Leveraging long time series for stream metabolism estimation. Journal of Geophysical Research: Biogeosciences, 123(2), pp.624-645. doi: 10.1002/2017JG004140

Bales, R.C., Molotch, N.P., Painter, T.H., Dettinger, M.D., Rice, R. and Dozier, J., 2006. Mountain hydrology of the western United States. Water Resources Research, 42(8). doi: 10.1029/2005WR004387

Barnhart, T.B., Tague, C.L. and Molotch, N.P., 2020. The counteracting effects of snowmelt rate and timing on runoff. Water Resources Research, 56(8), p.e2019WR026634. doi:10.1029/2019WR026634

Barnhart, T., Vukomanovic, J., Bourgeron, P. and Molotch, N., 2021. Future land cover and climate may drive decreases in snow wind-scour and transpiration, increasing streamflow at a Colorado, USA headwater catchment. Hydrological Processes, doi: 10.1002/hyp.14416

Baron, J., McKnight, D. and Denning, A.S., 1991. Sources of dissolved and particulate organic material in Loch Vale watershed, Rocky Mountain National Park, Colorado, USA. Biogeochemistry, 15(2), pp.89-110. doi: $10.1007 / \mathrm{BF} 00003219$

Boyer, E.W., Hornberger, G.M., Bencala, K.E. and McKnight, D.M., 1997. Response characteristics of DOC flushing in an alpine catchment. Hydrological processes, 11(12), pp.1635-1647. doi:10.1002/(SICI)10991085(19971015)11:12<1635::AID-HYP494>3.0.CO;2-H 
Brooks, P.D., Williams, M.W. and Schmidt, S.K., 1996. Microbial activity under alpine snowpacks, Niwot Ridge, Colorado. Biogeochemistry, 32(2), pp.93-113. doi: 10.1007/BF00000354

Brooks, P.D. and Williams, M.W., 1999. Snowpack controls on nitrogen cycling and export in seasonally snow-covered catchments. Hydrological processes, 13(14-15), pp.2177-2190. doi: 10.1002/(SICI)10991085(199910)13:14/15<2177::AID-HYP850>3.0.CO;2-V

Bueno de Mesquita, C.P., Tillmann, L.S., Bernard, C.D., Rosemond, K.C., Molotch, N.P. and Suding, K.N., 2018. Topographic heterogeneity explains patterns of vegetation response to climate change (19722008) across a mountain landscape, Niwot Ridge, Colorado. Arctic, Antarctic, and Alpine Research, 50(1), p.e1504492. doi: 10.1080/15230430.2018.1504492

Caine, N., 1992. Modulation of the diurnal streamflow response by the seasonal snowcover of an alpine basin. Journal of Hydrology, 137(1-4), pp.245-260. doi:10.1016/0022-1694(92)90059-5

Campbell, D.H., Clow, D.W., Ingersoll, G.P., Mast, M.A., Spahr, N.E. and Turk, J.T., 1995. Processes controlling the chemistry of two snowmelt-dominated streams in the Rocky Mountains. Water Resources Research, 31(11), pp.2811-2821. doi: 10.1029/95WR02037

Casson, N.J., Eimers, M.C. and Watmough, S.A., 2014. Sources of nitrate export during rain-on-snow events at forested catchments. Biogeochemistry, 120(1), pp.23-36. doi:10.1007/s10533-013-9850-4

Chen, Y., Wieder, W.R., Hermes A.L., and Hinckley, E.L.S., 2020. The role of physical properties in controlling soil nitrogen cycling across a tundra-forest ecotone of the Colorado Rocky Mountains, USA. Catena, 186, 104369.

Clow, D.W., 2010. Changes in the timing of snowmelt and streamflow in Colorado: a response to recent warming. Journal of Climate, 23(9), pp.2293-2306. doi:10.1175/2009JCLI2951.1

Dudley, R.W., Hodgkins, G.A., McHale, M.R., Kolian, M.J. and Renard, B., 2017. Trends in snowmeltrelated streamflow timing in the conterminous United States. Journal of Hydrology, 547, pp.208-221. doi: 10.1016/j.jhydrol.2017.01.051

Evans, C. and Davies, T.D., 1998. Causes of concentration/discharge hysteresis and its potential as a tool for analysis of episode hydrochemistry. Water Resources Research, 34(1), pp.129-137. doi:10.1029/97WR01881

Fisk, M.C., and Schmidt, S.K., 1995. Nitrogen mineralization and microbial biomass nitrogen dynamics in three alpine tundra communities. Soil Science Society of America Journal, 59(4), 1036-1043.

Godsey, S.E., Kirchner, J.W. and Clow, D.W., 2009. Concentration-discharge relationships reflect chemostatic characteristics of US catchments. Hydrological Processes: An International Journal, 23(13), pp.18441864. doi: 10.1002/hyp.7315

Goodman, K.J., Parker, S.M., Edmonds, J.W. and Zeglin, L.H., 2015. Expanding the scale of aquatic sciences: the role of the National Ecological Observatory Network (NEON). Freshwater Science, 34(1), pp.377-385. doi:10.1086/679459

Gribovszki, Z., Szilágyi, J. and Kalicz, P., 2010. Diurnal fluctuations in shallow groundwater levels and streamflow rates and their interpretation-A review. Journal of Hydrology, 385(1-4), pp.371-383. doi: 10.1016/j.jhydrol.2010.02.001

Hampton, S.E., Strasser, C.A., Tewksbury, J.J., Gram, W.K., Budden, A.E., Batcheller, A.L., Duke, C.S. and Porter, J.H., 2013. Big data and the future of ecology. Frontiers in Ecology and the Environment, 11(3), pp.156-162. doi: 10.1890/120103

Harpold, A., Brooks, P., Rajagopal, S., Heidbuchel, I., Jardine, A. and Stielstra, C., 2012. Changes in snowpack accumulation and ablation in the intermountain west. Water Resources Research, 48(11). W11501. doi: 10.1029/2012WR011949 
Heffernan, J.B. and Cohen, M.J., 2010. Direct and indirect coupling of primary production and diel nitrate dynamics in a subtropical spring-fed river. Limnology and oceanography, 55(2), pp.677-688. doi: 10.4319/lo.2010.55.2.0677

Hensley, R.T., McLaughlin, D.L., Cohen, M.J. and Decker, P.H., 2017. Stream phosphorus dynamics of minimally impacted coastal plain watersheds. Hydrological Processes, 31(8), pp.1636-1649. doi: 10.1002/hyp. 11132

Hood, E., Gooseff, M.N., and Johnson, S.L. 2006. Changes in the character of stream water dissolved organic carbon during flushing in three small watersheds, Oregon, Journal of Geophysical Research - Biogeosciences, 111, G01007, doi:10.1029/2005JG000082.

Hornberger, G.M., Bencala, K.E. and McKnight, D.M., 1994. Hydrological controls on dissolved organic carbon during snowmelt in the Snake River near Montezuma, Colorado. Biogeochemistry, 25(3), pp.147165. doi:10.1007/BF00024390

Hotchkiss, E.R. and Hall, R.O.J., 2014. High rates of daytime respiration in three streams: Use of $\delta 18 \mathrm{OO} 2$ and $\mathrm{O} 2$ to model diel ecosystem metabolism. Limnology and Oceanography, 59(3), pp.798-810. doi: 10.4319/lo.2014.59.3.0798

Jawitz, J.W. and Mitchell, J., 2011. Temporal inequality in catchment discharge and solute export. Water Resources Research, 47(10). doi: 10.1029/2010WR010197

Jennings, K.S. and Molotch, N.P., 2020. Snowfall fraction, cold content, and energy balance changes drive differential response to simulated warming in an alpine and subalpine snowpack. Frontiers in Earth Science, 8, p.186. doi:10.3389/feart.2020.00186

Kirchner, J.W., Godsey, S.E., Osterhuber, R., McConnell, J.R. and Penna, D., 2020. The pulse of a montane ecosystem: coupled daily cycles in solar flux, snowmelt, transpiration, groundwater, and streamflow at Sagehen and Independence Creeks, Sierra Nevada, USA. Hydrology and Earth System Sciences Discussions, 2020, pp.1-46. doi:10.5194/hess-2020-77

Koenig, L.E., Shattuck, M.D., Snyder, L.E., Potter, J.D. and McDowell, W.H., 2017. Deconstructing the effects of flow on DOC, nitrate, and major ion interactions using a high-frequency aquatic sensor network. Water Resources Research, 53(12), pp.10655-10673. doi:10.1002/2017WR020739

Kunkel, K.E., Palecki, M., Ensor, L., Hubbard, K.G., Robinson, D., Redmond, K. and Easterling, D., 2009. Trends in twentieth-century US snowfall using a quality-controlled dataset. Journal of Atmospheric and Oceanic Technology, 26(1), pp.33-44. doi: 10.1175/2008JTECHA1138.1

Lewis Jr, W.M. and Grant, M.C., 1980. Relationships between snow cover and winter losses of dissolved substances from a mountain watershed. Arctic and Alpine Research, 12(1), pp.11-17. doi:10.1080/00040851.1980.12004159

Li, D., Wrzesien, M.L., Durand, M., Adam, J. and Lettenmaier, D.P., 2017. How much runoff originates as snow in the western United States, and how will that change in the future?. Geophysical Research Letters, 44(12), pp.6163-6172. doi: 10.1002/2017GL073551.

Lunch, C.K., Laney, C.M. and NEON (National Ecological Observatory Network). 2021. neonUtilities: Utilities for Working with NEON Data. R package version 2.1.3. https://github.com/NEONScience/NEONutilities.

Lundquist, J.D. and Cayan, D.R., 2002. Seasonal and spatial patterns in diurnal cycles in streamflow in the western United States. Journal of Hydrometeorology, 3(5), pp.591-603. doi:10.1175/15257541(2002)003<0591:SASPID > 2.0.CO;2

Marshall, A.M., Abatzoglou, J.T., Link, T.E. and Tennant, C.J., 2019. Projected changes in interannual variability of peak snowpack amount and timing in the Western United States. Geophysical Research Letters, 
46(15), pp.8882-8892. doi:10.1029/2019GL083770

Maslov, M.N., and Maslova, O.A., 2021. Nitrogen limitation of microbial activity in alpine tundra soils along an environmental gradient: Intra-seasonal variations and effect of rising temperature. Soil Biology and Biochemistry, 156, 108234.

Meixner, T. and Bales, R.C., 2003. Hydrochemical modeling of coupled C and N cycling in high-elevation catchments: Importance of snow cover. Biogeochemistry, 62(3), pp.289-308. doi: 10.1023/A:1021118922787

Mulholland, P.J. and Hill, W.R., 1997. Seasonal patterns in streamwater nutrient and dissolved organic carbon concentrations: Separating catchment flow path and in-stream effects. Water resources research, 33(6), pp.1297-1306. doi: 10.1029/97WR00490

NEON (National Ecological Observatory Network) 2021a. Continuous discharge (DP4.20130.001). https://data.neonscience.org (accessed November 11, 2021)

NEON (National Ecological Observatory Network) 2021b. Water quality (DP1.20288.001). Water quality, RELEASE-2021 (DP1.20288.001). https://doi.org/10.48443/d8kw-5j62. Dataset accessed from https://data.neonscience.org on November 11, 2021

NEON (National Ecological Observatory Network) 2021c. Nitrate in surface water (DP1.20033.001). Nitrate in surface water, RELEASE-2021 (DP1.20033.001). https://doi.org/10.48443/924t-1k41. Dataset accessed from https://data.neonscience.org on November 11, 2021

NEON (National Ecological Observatory Network) 2021d. Temperature (PRT) in surface water (DP1.20053.001). https://doi.org/10.48443/ny19-pj91. Dataset accessed from https://data.neonscience.org on November 11, 2021

NEON (National Ecological Observatory Network) 2021e. Chemical properties of surface water (DP1.20093.001). https://doi.org/10.48443/05k7-e011. Dataset accessed from https://data.neonscience.org on November 11, 2021

Nimick, D.A., Gammons, C.H. and Parker, S.R., 2011. Diel biogeochemical processes and their effect on the aqueous chemistry of streams: A review. Chemical Geology, 283(1-2), pp.3-17. doi:10.1016/j.chemgeo.2010.08.017

Osborne, B.B., Baron, J.S., and Wallenstein, M.D., 2016. Moisture and temperature controls on nitrification differ among ammonia oxidizer communities from three alpine soil habitats. Frontiers of Earth Science, 10(1), $1-12$.

Pellerin, B.A., Saraceno, J.F., Shanley, J.B., Sebestyen, S.D., Aiken, G.R., Wollheim, W.M. and Bergamaschi, B.A., 2012. Taking the pulse of snowmelt: in situ sensors reveal seasonal, event and diurnal patterns of nitrate and dissolved organic matter variability in an upland forest stream. Biogeochemistry, 108(1), pp.183-198. doi:10.1007/s10533-011-9589-8

Rauscher, S.A., Pal, J.S., Diffenbaugh, N.S. and Benedetti, M.M., 2008. Future changes in snowmelt-driven runoff timing over the western US. Geophysical Research Letters, 35(16). doi: 10.1029/2008GL034424

Rode, M., Wade, A.J., Cohen, M.J., Hensley, R.T., Bowes, M.J., Kirchner, J.W., Arhonditsis, G.B., Jordan, P., Kronvang, B., Halliday, S.J. and Skeffington, R.A., 2016. Sensors in the stream: the high-frequency wave of the present. Environmental Science and Technology, 50(19), pp.10297-10307. doi:10.1021/acs.est.6b02155

Rusjan, S., \& Mikoš, M. (2010). Seasonal variability of diurnal in-stream nitrate concentration oscillations under hydrologically stable conditions. Biogeochemistry, 97(2-3), 123-140. https://doi.org/10.1007/s10533009-9361-5

Sebestyen, S.D., Boyer, E.W., Shanley, J.B., Kendall, C., Doctor, D.H., Aiken, G.R. and Ohte, N., 2008. Sources, transformations, and hydrological processes that control stream nitrate and dissolved or- 
ganic matter concentrations during snowmelt in an upland forest. Water Resources Research, 44(12). doi:10.1029/2008WR006983.

Sievering, H., Burton, D. and Caine, N., 1992. Atmospheric loading of nitrogen to alpine tundra in the Colorado Front Range. Global Biogeochemical Cycles, 6(4), pp.339-346. doi: 10.1029/92GB01513

Sickman, J.O., Leydecker, A. and Melack, J.M., 2001. Nitrogen mass balances and abiotic controls on N retention and yield in high-elevation catchments of the Sierra Nevada, California, United States. Water Resources Research, 37(5), pp.1445-1461. doi: 10.1029/2000WR900371

Sickman, J.O., Leydecker, A.L., Chang, C.C., Kendall, C., Melack, J.M., Lucero, D.M. and Schimel, J., 2003. Mechanisms underlying export of $\mathrm{N}$ from high-elevation catchments during seasonal transitions. Biogeochemistry, 64(1), pp.1-24. doi: 10.1023/A:1024928317057

Siirila-Woodburn, E.R., Rhoades, A.M., Hatchett, B.J., Huning, L.S., Szinai, J., Tague, C., Nico, P.S., Feldman, D.R., Jones, A.D., Collins, W.D. and Kaatz, L., 2021. A low-to-no snow future and its impacts on water resources in the western United States. Nature Reviews Earth \& Environment, 2(11), pp.800-819. doi: 10.1038/s43017-021-00219-y

Sturm, M., Goldstein, M.A. and Parr, C., 2017. Water and life from snow: A trillion dollar science question. Water Resources Research, 53(5), pp.3534-3544. doi:10.1002/2017WR020840

Sueker, J.K., Clow, D.W., Ryan, J.N. and Jarrett, R.D., 2001. Effect of basin physical characteristics on solute fluxes in nine alpine/subalpine basins, Colorado, USA. Hydrological Processes, 15(14), pp.2749-2769. doi: $10.1002 /$ hyp. 265

Tobias, C.R., Böhlke, J.K. and Harvey, J.W., 2007. The oxygen-18 isotope approach for measuring aquatic metabolism in high productivity waters. Limnology and Oceanography, 52(4), pp.1439-1453. doi: 10.4319/lo.2007.52.4.1439

Viviroli, D., Durr, H.H., Messerli, B., Meybeck, M. and Weingartner, R., 2007. Mountains of the world, water towers for humanity: Typology, mapping, and global significance. Water resources research, 43(7), W07447, doi:10.1029/2006WR005653

Williams, M.W. and Melack, J.M., 1991a. Precipitation chemistry in and ionic loading to an alpine basin, Sierra Nevada. Water Resources Research, 27(7), pp.1563-1574. doi: 10.1029/90WR02773

Williams, M.W. and Melack, J.M., 1991b. Solute chemistry of snowmelt and runoff in an alpine basin, Sierra Nevada. Water Resources Research, 27(7), pp.1575-1588. doi: 10.1029/90WR02774

Williams, M.W., Brooks, P.D., Mosier, A. and Tonnessen, K.A., 1996a. Mineral nitrogen transformations in and under seasonal snow in a high-elevation catchment in the Rocky Mountains, United States. Water Resources Research, 32(10), pp.3161-3171. doi: 10.1029/96WR02240

Williams, M.W., Losleben, M., Caine, N. and Greenland, D., 1996b. Changes in climate and hydrochemical responses in a high-elevation catchment in the Rocky Mountains, USA. Limnology and Oceanography, 41(5), pp.939-946. doi: 10.4319/lo.1996.41.5.0939

Williams, M.W., Brooks, P.D. and Seastedt, T., 1998. Nitrogen and carbon soil dynamics in response to climate change in a high-elevation ecosystem in the Rocky Mountains, USA. Arctic and Alpine Research, 30(1), pp.26-30. doi: 10.1080/00040851.1998.12002872

Williams, M., J. Knowles, R. Cowie, and Niwot Ridge LTER. $2021 . \quad$ Streamflow data for Como creek, 2006 - 2014 ver $1 . \quad$ Environmental Data Initiative. https://doi.org/10.6073/pasta/82fd3feabda2b0e200ef4b85bc18a5ea (Accessed 2021-10-01)

Williams, M. 2021. Stream water chemistry data for Como creek, 1998-2013 ver 1. Environmental Data Initiative. https://doi.org/10.6073/pasta/203daf080eae3403e1f900292c4fd0fb (Accessed 2021-10-01) 

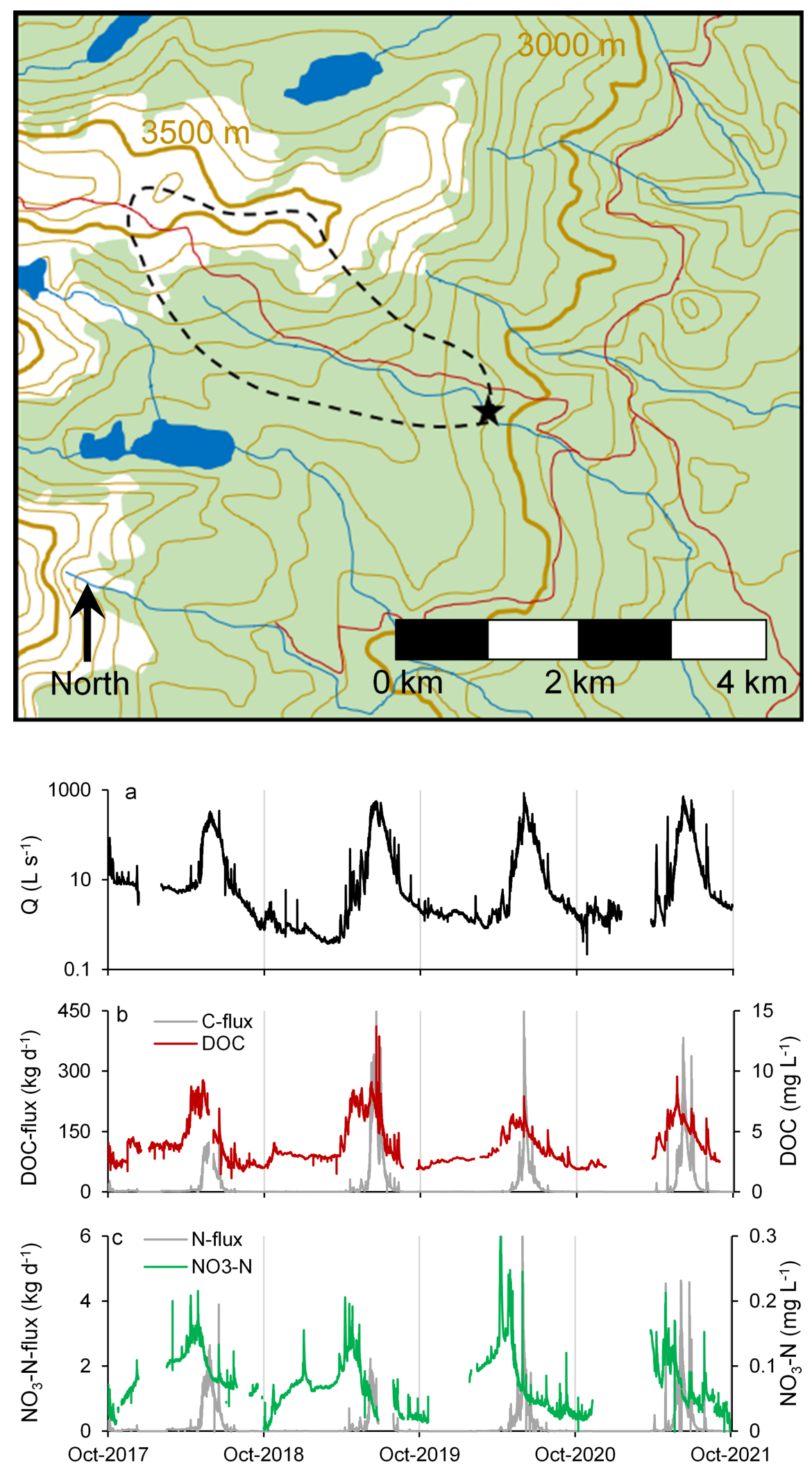

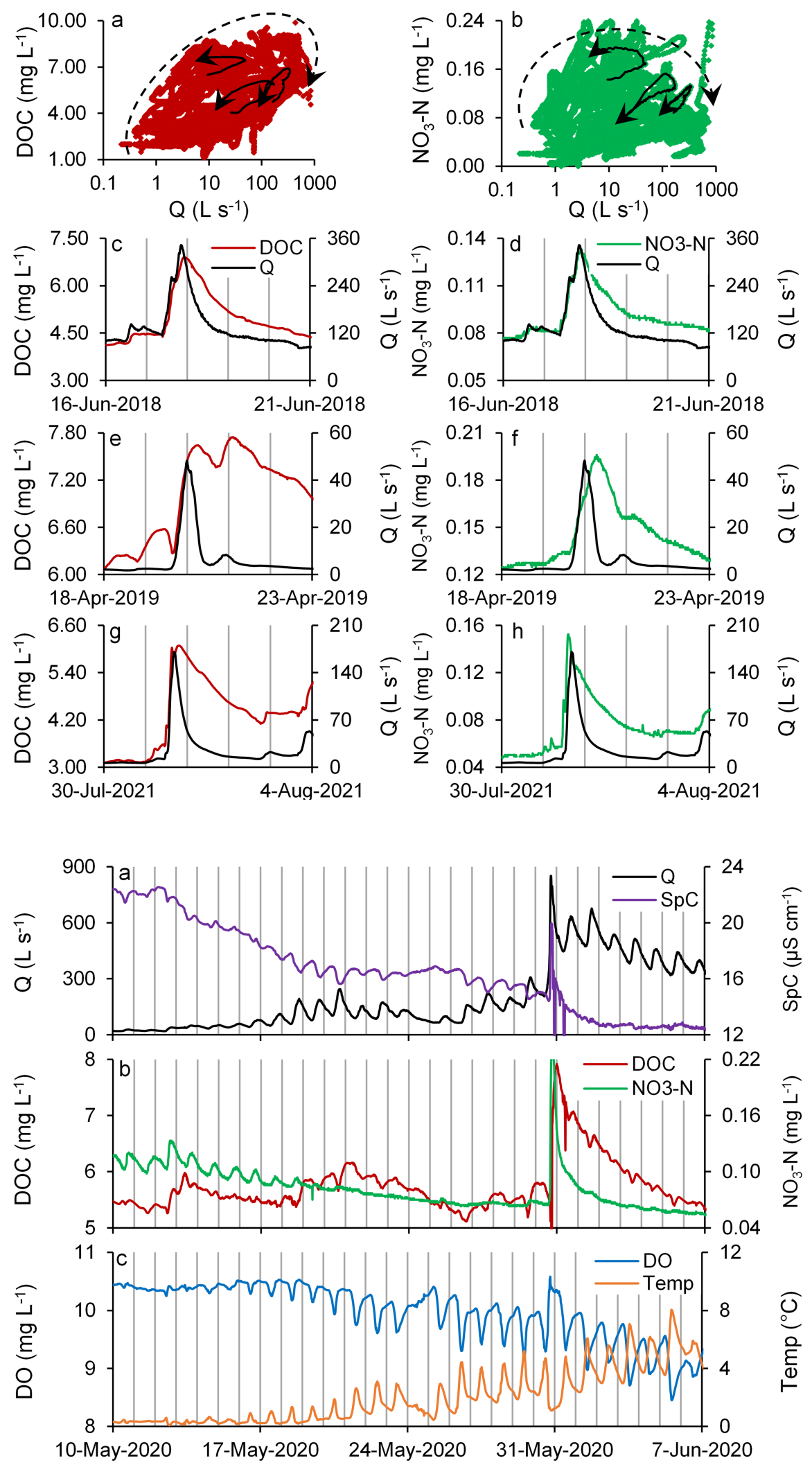


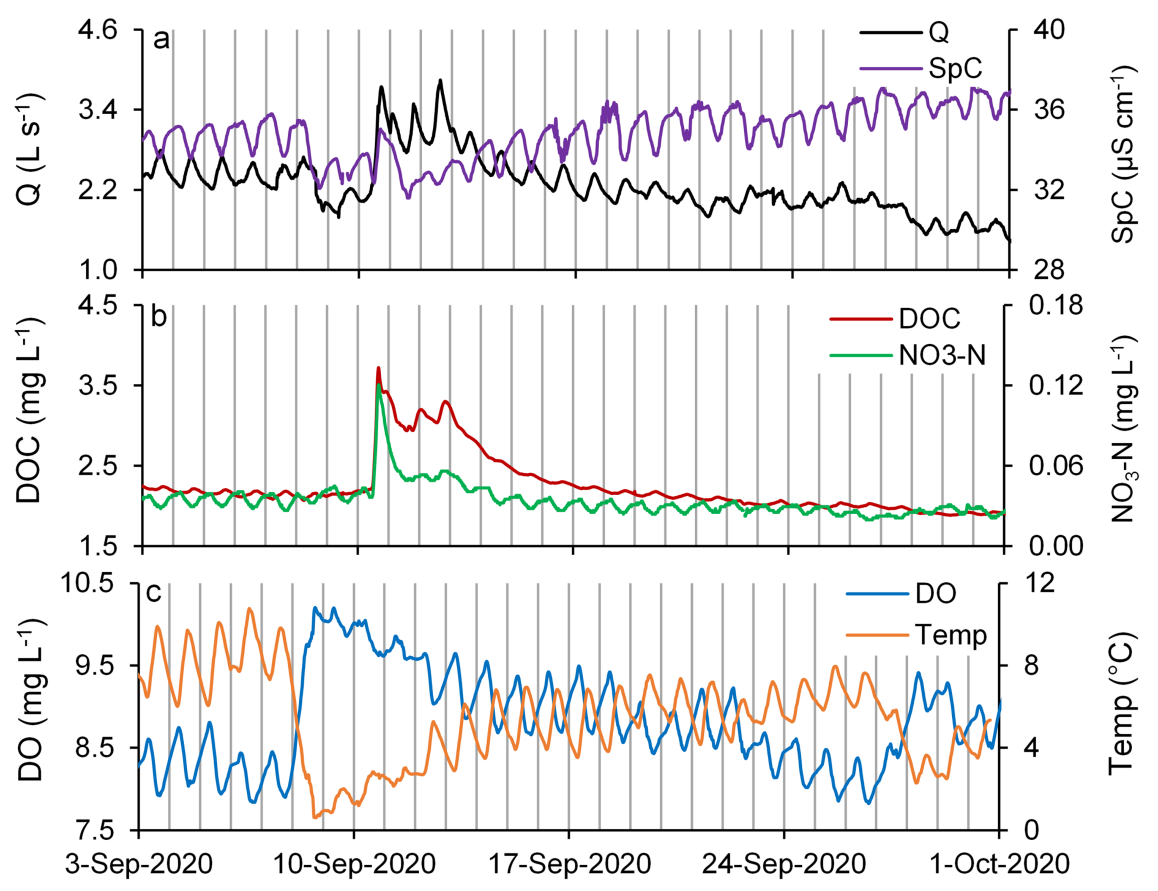



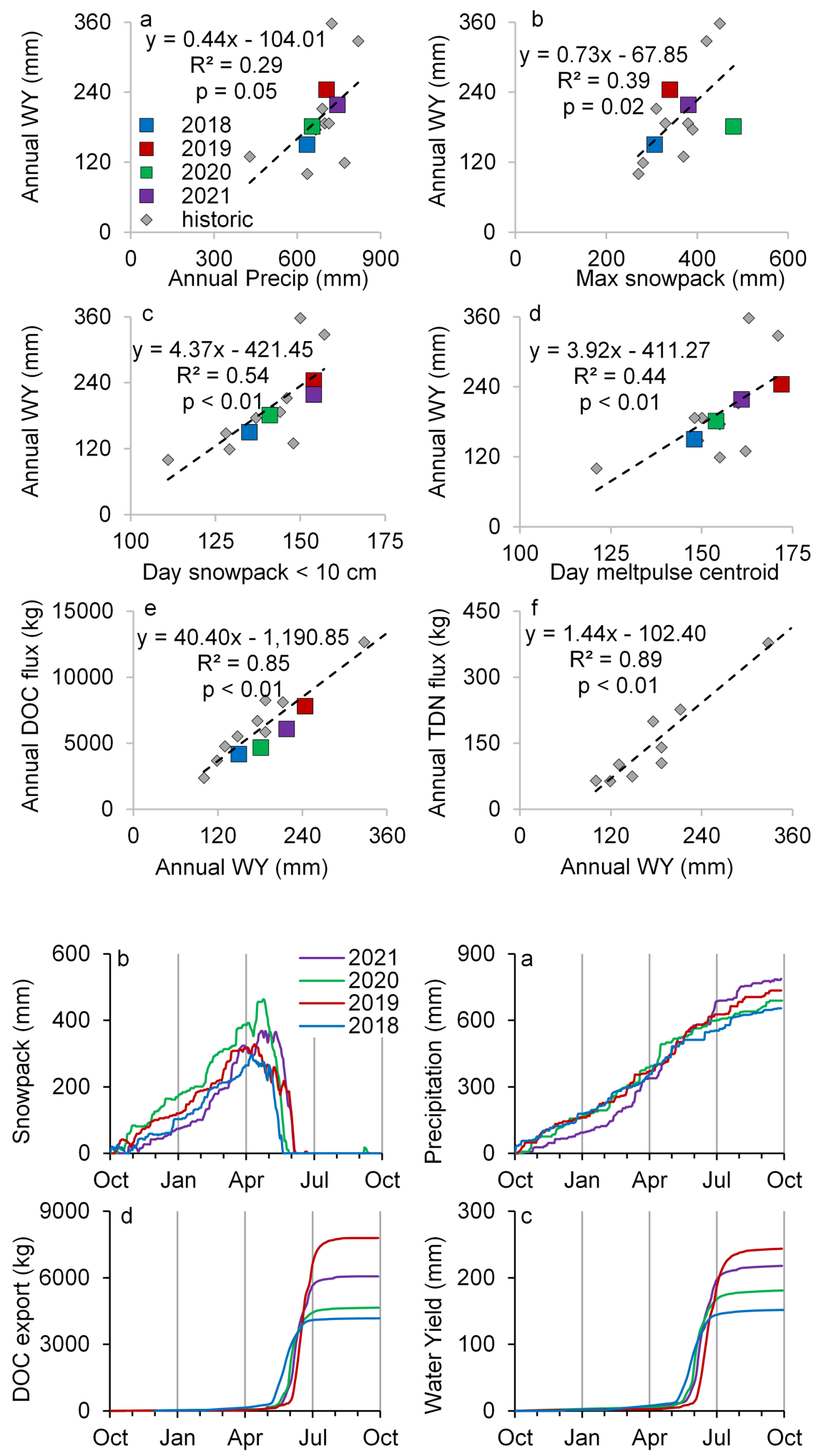